\title{
Covid-19: Doctors challenge legality of government's PPE guidance
}

\author{
Clare Dyer
}

The BMJ

Two doctors have launched an urgent legal challenge to guidance by NHS England on personal protective equipment (PPE), which they claim fails to protect them from infection with covid-19.

Meenal Viz, a clinical fellow in medicine, and her husband Nishant Joshi, a GP trainee, claim that the guidance, which was issued at a time of continuing shortages of masks and gowns, fails to comply with international standards set by the World Health Organization or domestic legislation on health and safety at work.

Viz, who is pregnant, recently demonstrated outside 10 Downing Street about shortages of PPE, and Joshi is currently doing a stint in a hospital as part of his training. Both have been exposed to patients with covid-19.

Represented by the law firm Bindmans, they say they are concerned that the guidance is unclear about the level of PPE that is considered acceptable, the risks to frontline staff with different levels of PPE, and the right to refuse to work without adequate levels of PPE.

They accuse Matt Hancock, health and social care secretary for England, of failing to arrange the mass procurement of PPE either in the UK or through the EU and say that recent changes to the guidance downgraded the level of protection for NHS staff. Both Viz and Joshi are British Asians, and they argue that the guidance fails to tackle the greater risks faced by black and Asian healthcare workers. Of the 19 doctors and dentists who have died from covid-19, 18 were from ethnic minority backgrounds.

NHS Procurement, NHS Employers, and Health Education England have been included as interested parties in the legal challenge and have been sent a copy of the pre-action letter that was sent to Hancock and NHS England.

Joshi told The BMJ, "We are concerned that the guidelines were based on supply rather than science, and indeed Matt Hancock openly admitted today on Good Morning Britain that 'the guidelines are based on the use of our precious resources.' It's a matter of life and death so I would hope they take it seriously."

Basmah Sahib, the solicitor for Viz and Joshi, said, "Almost all of us have a friend or loved one who is putting their life at risk to care for patients with covid-19. The least they deserve is honesty, clear guidance, and proper support from the secretary of state to feel safe and protected at work.

"No healthcare worker should face disciplinary action just for requesting proper protective equipment. We hope the guidance will be brought up to the standards of WHO and that hospitals will update their practices accordingly."

In response to the pre-action letter, a Public Health England spokesperson said, "The safety of those working on the front line in health and social care is our number one priority. The UK guidance, written with NHS leaders and agreed by all four chief medical officers, in consultation with royal and medical colleges, recommends the safest level of personal protective equipment. WHO has confirmed that UK guidance is consistent with what it recommends for the highest risk procedures."

1 Rimmer A. Two-thirds of healthcare workers who have died were from ethnic minorities. BMJ 2020;369:m16210.1136/bmj.m1621.

Published by the BMJ Publishing Group Limited. For permission to use (where not already granted under a licence) please go to http://group.bmj.com/group/rights-licensing/ permissions 